\title{
Substantiation of the parameters of vibration systems in the cab of the gantry crane at the workplace of crane operators
}

\author{
Kirill O. Kobzev ${ }^{1, *}$, Sergey A. Shamshura ${ }^{1}$, Alexander N. Chukarin ${ }^{2}$, and \\ Alexey I. Buryanov ${ }^{3}$, and Valeriy E. Kasyanov ${ }^{1}$ \\ ${ }^{1}$ Don State Technical University, 344000 Rostov-on-Don, Russia \\ ${ }^{2}$ Rostov State Transport University, 344038 Rostov-on-Don, Russia \\ ${ }^{3}$ State Scientific Establishment "Agriculture research center "Donskoy", North Caucasus Institute of \\ Mechanization and Electrification of Agriculture, 347740 Zernograd, Russia
}

\begin{abstract}
Reduction of vibration in the cabin can be achieved by increasing the area of vibration absorption by placing on the ceiling and floor vibro-absorbing facings. The process of absorption of vibration occurs due to the transition of the energy of oscillating particles to heat due to frictional losses in the pores of the material; therefore, for effective vibration absorption, the material must have a porous structure, the pores must be open from the side of the vibration and join together (unclosed pores) so as not to prevent the penetration of the vibration wave into the thickness of the material. As a vibration-absorbing cladding, we use a construction in the form of a layer of a homogeneous porous material of a certain thickness, reinforced directly on the surface of the fence.
\end{abstract}

Throughout the world, when working in warehouses, performing construction, installation, transportation and loading operations, gantry cranes are used. In the gantry cranes, the maximum value is given to the lifting capacity, lifting height, service area, high productivity, the ability to position cargoes as precisely as possible, to high reliability indicators, and the truck's own stability and crane stability are also given the utmost attention. Preservation of health and efficiency of operators of gantry cranes from the influence of hazardous and harmful factors is one of the fundamental problems in the field of labor protection on cranes of various purposes in industry. On a number in comparison of cranes of various purposes, gantry cranes are the subject of increased danger. When gantry cranes work, not only service personnel are exposed to danger, but also persons in the working area of the lifting device. There are three main causes of accidents on gantry cranes - the destruction of ropes, the destruction of structural elements and fatigue of operators. The main harmful factor, the long-term effect of which affects the operator's fatigue and consequently leads to a decrease in labor productivity and occupational diseases, is vibration. The carried out analysis of scientific works has shown that the question of the influence of vibration characteristics in cabins of gantry cranes at workplaces on the safety of operators has not been sufficiently studied. In connection with

\footnotetext{
*Corresponding author: kobzevkirill1990@mail.ru
} 
the foregoing, the task of lowering the level of vibration to sanitary standards in cabins of gantry cranes at crane workplaces is urgent and will affect scientific, technical, social and economic significance.

Since the aim of the study in this case is to investigate the vibrations in the operator's workplaces, the main element is the floor of the cabin, on which the crane operator's chair is installed. It should be noted that the calculation of the vibration reduction system is performed in the normalized range of $8-63 \mathrm{~Hz}$ (in contrast to the normalized audio frequency range $31.5-8000 \mathrm{~Hz}$ ). As a calculation scheme, the traditional model of the operator's chair.
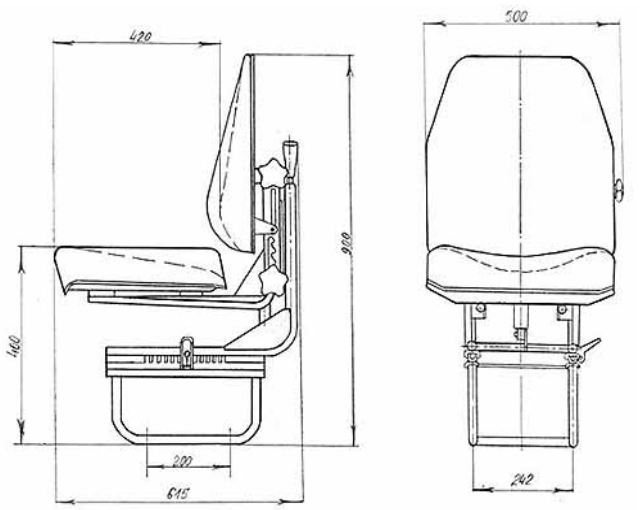

Fig. 2. Gantry crane operator's chair

The difference between the approach proposed in this article is that the force influence on the operator's chair is created by the vibrations of the floor of the cabin according to the formula

$$
P(t)=k_{m} \cdot m_{1} \cdot V_{i 1} \cdot f_{i} \cdot j_{i n} \sin 2 \pi f_{i} t,
$$

where $m_{1}$ - floor weight, $\mathrm{kg} ; V_{i 1}$ - the speed of floor oscillations in the normalized frequency range of 8-63 Hz, $-\mathrm{M} / \mathrm{c}, k_{m}$ - coefficient of clutch thrust joggle movement.

Then from the oscillation equation

$$
m_{0} \frac{d^{2} z}{d t^{2}}+c z=P(t)
$$

From this equation, the speed of oscillations is determined

$$
z^{\prime}=\left|\frac{P \omega_{i}}{c-\omega_{i}^{2} m_{2}}\right|,
$$

where $m_{2}$ - weight of chair and crane operator, кг; с - hardness of the workplace, N/m.

Then the level of the velocity of oscillations is expressed by the following relationship

$$
L_{V}=20 \lg \frac{P \omega_{i}}{c-\omega_{i}^{2} m_{2}} \cdot 2 \cdot 10^{7}
$$


To fulfill the sanitary standards of vibration, the actual value of the vibration level should be reduced to the required value, which in turn is determined by the effective coefficients of the vibrational energy loss known by the dependence

$$
\Delta L=10 \lg \frac{\eta}{\eta_{0}}
$$

where $\eta$ - value of the total loss factor of the vibrational energy of the vibration protection system; $\eta_{0}$ - value of the coefficient of losses of the vibrational energy of the substrate.

Then the limit-permissible value is substituted for the left-hand side of the expression for vibration levels and, taking into account expressions (3) and (4), the following relationship is obtained:

$$
L_{V}=20 \lg \frac{P \omega_{i}}{c-\omega_{i}^{2} m_{2}} \cdot 2 \cdot 10^{7}-20 \lg \left(\frac{\eta}{\eta_{0}}\right)^{0,5},
$$

As can be seen from the expression obtained, the vibration levels are determined not only by the geometric and physicomechanical parameters of the cabin itself and the conditions of its fixing on the carrier system, but also by the shock coefficient, which in turn affects the smoothness of the moving of the freight trolley. The smoothness of the clutch stroke, responsible for the smooth movement of the load trolley, is estimated by the precision factor that will be considered later.

Performing the corresponding transformations, the dependence (5) is reduced to the following form

$$
5 \cdot 10^{7} \frac{P \omega_{i}}{c-\omega_{i}^{2} m_{2}} \sqrt{\eta_{0}}=\sqrt{\eta} \cdot 10^{0,05 L_{c}}
$$

From the obtained equation, the necessary coefficient of losses of the vibrational energy of the vibration protection system of the operator of the gantry crane cab

$$
\eta=25 \frac{P^{2} \omega_{i}^{2} \eta_{0}}{\left(c-\omega_{i}^{2} m_{2}\right)^{2}} 10^{14-0,1 L_{c}}
$$

The cab of the gantry crane is subjected to simultaneous action of internal and external sources of vibration resulting from the transfer to all parts of the enclosures of the cabs from the working bodies and in particular, reproduced during the movement of the gantry crane.

The force effects when moving depend on the mass and can be seen from these equations, the mass is largely determined by the flywheel moment of the coupling.

Having considered the calculation procedure for the clutch and running wheels, the general form of the mechanism of movement of the gantry crane of the gantry crane and the analysis of the dynamic system in constantly changing positions are used in the form of the expression of linear, independent and ordinary differential equations of the first type:

$$
\frac{d X}{d t}=F(X, t, M)
$$

The calculation is actually performed on the transmitted torque. Taking into account the recalculation of inertial, elastic and dissipative characteristics, the equations of the selected gearmotor circuit can be written in the form: 


$$
\begin{aligned}
& J_{k} \frac{d \Omega_{k}}{d t}+\beta_{k} \Omega_{k}=M_{k}-M_{k+1} \\
& M_{k, k+1}=C_{k, k+1}\left(\varphi_{k}-\varphi_{k+1}\right)+\beta_{k, k+1}\left(\Omega_{k}-\frac{1}{i_{k, k+1}} \Omega_{k+1}\right),
\end{aligned}
$$

where $J_{k}$ - moment of inertia; $M_{k} M_{k+1}$ - rotating moments; $C_{k, k+1}$ - rigidity of elastic elements; $\beta_{k, k+1}-$ damping factors; $i_{k, k+1}-$ transfer relations; $\varphi_{k} \varphi_{k+1}-$ torsional deformations; $\Omega_{k} \Omega_{k+1}-$ angular velocities.

When constructing the model of the investigated gearbox, the gaps in the gears are taken into account.

The eigenvalue of the equation in this research scheme, using this matrix formation scheme, can be written in the form $-\frac{d X}{d t}$.

$$
\frac{d X}{d t}=A X+R(X, t)
$$

where A- own operator of the dynamic system of the reducer; $\mathrm{X}$ - state vector; $\mathrm{X}$ - vector of right-hand sides of the system of equations.

The received system of the equations and allows to define the twisting moments on the basis of which it is possible to justify the design parameters of the coupling.

Taking into account the nonlinearity of the elastic characteristics of the coupling, it is necessary to carry out by introducing additional operators into the vector of the right-hand sides of the matrix equation of the system under study.

In this expression, taking into account the coupling, we obtain a system of

$$
\begin{gathered}
J_{d v} \frac{d \Omega_{d v}}{d t}+\beta_{d v} \Omega_{d v}=M_{d v}-M_{1 M} ; \\
J_{1 M} \frac{d \Omega_{1 M}}{d t}+\beta_{1 M} \Omega_{1 M}=M_{1 M}-M_{M} ; \\
\text { equations: } J_{2 M} \frac{d \Omega_{2 M}}{d t}+\beta_{2 M} \Omega_{2 M}=M_{M}-M_{V} ; \\
\frac{d M_{1 M}}{d t}=C_{1 M}\left(\Omega_{d v}-\Omega_{1 M}\right)+\beta_{1 M}\left(\frac{d \Omega_{d v}}{d t}-\frac{d \Omega_{1 M}}{d t}\right) ; \\
\frac{d M_{M}}{d t}=C_{M}\left(\Omega_{1 M}-\Omega_{2 M}\right)+\beta_{M}\left(\frac{d \Omega_{1 M}}{d t}-\frac{d \Omega_{2 M}}{d t}\right),
\end{gathered}
$$

where $\Omega_{M_{1}}$ - the angular velocity of the first coupling half; $\Omega_{M_{2}}-$ angular velocity of the second half-coupling; $C_{M}$ - clutch stiffness value; $\beta_{M}-$ clutch damping factor value; $M_{M}$-torque value transmitted by the clutch.

On the basis of the above calculations, it can be concluded that the use of an elastic coupling with screw springs will help reduce the loads in the mechanism, and, consequently, also a more stable operation of the crane. As for the oscillations that arise in the mechanism: with increasing elastic properties of the clutch, the frequency of natural oscillations increases, but does not exceed admissible norms. Thus, resonance does not 
occur in this system and the use of an elastic coupling is possible provided that springs of appropriate rigidity are installed.

\section{References}

1. Ji. A. Borisov, G. D. Yanovsky, Acoustic suspended ceilings with sound-absorbing mineral wool products (Tr. Central Research Institute of Industrial Facilities, Moscow, 1981)

2. I. I. Bogolepov, B. M. Efimtsev, V. F. Panin, Tr. TsAGI, 1920, 39 (1978)

3. E. I. Avferonok, N. G. Belyakovskiy, I. I. Bogolepov et al, Reference book on ship acoustics (Shipbuilding, Leningrad, 1978)

4. S. P. Timoshenko, S. Voinovsky-Krieger, Plates and shells (Science, Moscow, 1966)

5. A. C. Nikiforov, Acoustic design of ship structures: Reference book (Shipbuilding, Leningrad, 1990)

6. N. I. Ivanov, Combating noise and vibrations on track and construction machines (Transport, Moscow, 1987)

7. L. G. Ba-lishanskaya, L. F. Drozdova, N. I. Ivanov et al. Ed. N.I. Ivanova, Technical acoustics of transport vehicles: Reference book (Polytechnica, Saint Petersburg, 1992)

8. N. I. Ivanov, A. C. Nikiforov, Fundamentals of vibroacoustics (Polytechnica, Saint Petersburg, 2000)

9. L. P. Borisov, D. R. Guzhas, Soundproofing in mechanical engineering (Mechanical engineering, Moscow, 1990)

10. N. I. Ivanov, Engineering acoustics. Theory and practice of noise control: a textbook (University book, Logos, Moscow, 2008)

11. V. A. Gergert, Reduction of noise at the workplaces of road train drivers by providing the required soundproofing properties and dissipative parameters of the cabin: (Author's abstract. dis. Cand. tech. sciences, 2002)

12. V. Z. Vlasov, Selected works in 3 volumes, III (Publishing House of the USSR Academy of Sciences, Moscow, 1963)

13. A. N. Chukarin, Theory and methods of acoustic calculations and design of technological machines for machining: monograph (Publishing Center of the State Technical University, Rostov n / a, 2004) 